\section{Socio-demographic correlates of depressive and anxiety symptoms among Jamaicans during the COVID-19 pandemic: A Rapid Online Survey}

Patrice Whitehorne-Smith ${ }^{1}$, Gabrielle Mitchell ${ }^{2}$, Althea Bailey $^{2}$, Chinwendu ${ }^{3}$ Agu, Kayan Campbell Williams ${ }^{2}$, Daniel Oshi ${ }^{2}$, Joy Harrison ${ }^{2}$, Wendel Abel $^{2}$

1 School of Public Health, Curtin University, Perth, Australia

${ }^{2}$ Dept of Community Health \& Psychiatry, University of the West Indies, Mona, Jamaica

3 The UWI School of Nursing, University of the West Indies, Mona, Jamaica

\section{Corresponding Author}

Name : Gabrielle Mitchell

Institution: Dept of Community Health and Psychiatry,

The University of the West Indies, Mona

Address: 3 Gibraltar Camp Rd, Kgn 7, Jamaica

Email: gabrielle.mitchell@uwimona.edu.jm, gabmitchell@gmail.com

\section{DOI: $10.48107 / C M J .2021 .05 .002$}

Copyright: This is an open-access article under the terms of the Creative Commons Attribution License which permits use, distribution, and reproduction in any medium, provided the original work is properly cited.

(C)2021 The Authors. Caribbean Medical Journal published by Trinidad \& Tobago Medical Association

\section{ABSTRACT}

\section{Objectives}

This study sought to investigate the prevalence and socio -demographic correlates of depressive and anxiety symptoms among Jamaicans during the ongoing COVID19 pandemic.

\section{Methods}

This was a cross-sectional, population-based online survey. Persons 18 years and older, who reside in Jamaica were targeted via the Facebook social media platform. Those interested in participating were routed to a separate survey platform. The questionnaire captured data related to socio-demographics, knowledge of COVID19, and beliefs and attitudes about COVID-19. Mental health issues including depressive and anxiety symptoms were assessed with questionnaire items from the Patient Health Questionnaire (PHQ-2) and the Generalized Anxiety Disorder (GAD-2).

\section{Results}

There were 485 participants in the study $(90.8 \%$ female and $9.2 \%$ male). Almost all (97.7\%) of participants felt that COVID-19 had greatly affected their lives. The prevalence of notable depressive symptoms and anxiety symptoms was $54.7 \%$ and $49.2 \%$ respectively. Binary logistic regression found significant associations between younger age, lower educational level, unemployment and significant depressive symptoms. While younger age and lower educational level were associated with significant anxiety symptoms.

\section{Conclusion}

The findings suggest the need for the government to develop targeted mental health initiatives for young adults, the under- or unemployed and those with lower levels of education. 


\section{INTRODUCTION}

The Coronavirus disease (COVID-19), a novel, rapidly progressing and highly infectious respiratory disease, has caused a devastating pandemic which has impacted livelihoods worldwide and contributed to significant loss of life (World Health Organisation [WHO]) . ${ }^{1}$ The pace of this pandemic poses one of the most serious public health emergencies in the last century. ${ }^{2}$

Current studies suggest that the psychological stressors and reactions to COVID-19 are prevalent across the world. Therefore, addressing the effects of this disease on mental health is urgent. ${ }^{3-5}$ COVID-19 can lead to a generalised, heightened fear of the disease across a population. ${ }^{6,7}$ Furthermore, the psychological impact of quarantine is high with reported isolation stressors including quarantine duration, fear of infection, frustration, inadequate supplies and living situation, and inadequate information and financial loss. ${ }^{3,4,8}$

Commonly reported psychological reactions to isolation measures include anxiety and depressive symptoms as well as self-reported stress. ${ }^{3,4}$ These psychological reactions have also been linked to sociodemographic factors as well as knowledge, attitudes and practices around the virus. ${ }^{5}$ Some studies indicate that level of knowledge, optimistic attitudes and employment of preventative measures are linked to lower levels of anxiety symptoms. ${ }^{5}$ Emerging evidence also suggests that some sociodemographic groups may be more susceptible to COVID-19 related anxiety and depressive symptoms, with gender and employment status frequently cited in the literature. ${ }^{4,8}$ Therefore, it is pertinent to assess the psychological reactions and impact of the general public who are currently experiencing COVID-19 mitigation strategies, which may represent a disruption of their daily lives and who may be unwittingly exhibiting stigmatising behaviours. ${ }^{9-11}$

In Jamaica, various public health measures to combat the spread of COVID-19 were implemented. These measures included public health and psycho-education campaigns about COVID-19, in tandem with various mitigation strategies to reduce the spread. Measures taken to reduce the spread of COVID-19 involved partial restriction of movement, mask-wearing protocols, curfews, lock down, isolation and quarantine measures for suspected and confirmed COVID-19 cases. These measures have also been associated with stressors such as job loss, job uncertainty, financial stress, family strain, loss of routine and reduced social contact, which could further snowball into mental health concerns such as anxiety and depression due to persistent feelings of fear and the rapid changes to daily life. , $^{911,12}$

Currently, scientific study on the impact of COVID-19 in Jamaica is rapidly emerging, however, evidence on the relationship between COVID-19 and mental health in Jamaica, and more broadly, in the Caribbean region, is lacking. There is a need to better understand this relationship as it may contribute to guiding the country's public health response to the pandemic. Therefore, this study sought to provide insights into the association between COVID-19 and mental health among Jamaicans. Specifically, the objectives of the study were: (i) to investigate the prevalence of depressive and anxiety symptoms among the Jamaican population during the COVID-19 pandemic; (ii) to determine the sociodemographic factors associated with depressive and anxiety symptoms during the COVID-19 pandemic in the Jamaican population.

\section{METHODS}

\section{Study Design}

This was a descriptive, cross-sectional study, which utilised an online survey. Due to the pace, novelty and severity of this disease, methods of assessment of its impact need to be completed within shorter time frames, especially when considering the constantly evolving nature of research findings. ${ }^{13}$ However, given the longer timeframe (many months) that nationally representative household surveys take to complete, this was not a feasible option for this pandemic. ${ }^{14}$ Extant literature suggests that rapid online surveys provide a solution to the time-sensitive nature of pandemic research. ${ }^{14,15}$ Rapid online surveys have notable merits. These include their usage as social distance data collecting methods; they facilitate the speed at which planning the survey and publishing of the results can occur, while reaching a wider population and geographic range. ${ }^{16}$ Also, providing access to many different online and social media platforms (i.e., SurveyMonkey, WhatsApp, Facebook, Twitter etc.) to disseminate surveys. ${ }^{16}$ Cost, ease of implementation and increased anonymity are also valuable advantages in the use of this method of data collection. ${ }^{16}$ These are crucial elements especially when lockdown measures are in effect. 
The target population consisted of persons 18 years and older who resided in Jamaica at the time of the study and who were active users of their Facebook accounts. The sample size was calculated using Raosoft online sample size calculator. Using a confidence interval of $95 \%$ and $5 \%$ margin of error and a response distribution of $50 \%$, the minimum required sample size arrived at was 385 to be considered as representative. Non-probability sampling was employed; however, to increase the statistical power of the study, data collection was continued until a sample size of 485 participants was reached.

Facebook advertisements were used to recruit persons for the study by directing interested persons to click a link to study questionnaire. The data was collected between August and September 2020.

Ethical Approval for the study was granted through the Ministry of Health and Wellness Research Advisory Panel on Ethics and Medico-Legal Affairs Committee as well as from the University of the West Indies Faculty of Medical Sciences Ethical Research Committee. All participants provided online informed consent prior to participating in the study.

\section{Data Collection Instrument and Procedures}

A self-administered questionnaire on the Influence of COVID-19 on Coping and Well-being developed by the researchers was used for data collection. The research team included medical practitioners, public health specialists and psychologists. Research specialists conducted a review of the instrument to ascertain the appropriateness, accuracy and clarity of the instrument.

The instrument had two sections. Section A captured the sociodemographic characteristics of participants such as gender, age, marital status, area of residence, employment status and education level. Section B included questions with sub-sections assessing whether the participants had heard about COVID-19, beliefs about coercive control of COVID-19 (relating to stigma), personal protective attitudes towards COVID-19 and mental wellbeing during the pandemic. Depressive symptoms were measured using the Patient Health Questionnaire-2 (PHQ-2) which is a two-item Likert scale brief screening tool for depressive symptoms over the last two weeks associated with Major Depressive Disorder. ${ }^{17}$ Similarly, anxiety symptoms were measured using the Generalised Anxiety Disorder (GAD)-2 scale. ${ }^{18}$
The Patient Health Questionnaire- 2 (PHQ-2) is often used as a brief screening tool for symptoms of depression. PHQ-2 scores range between zero to six. In comparing this scale with the criterion standard, which is an interview carried out by a mental health professional, a score of three or greater had a sensitivity of $83 \%$ and specificity of $92 \%$ for major depression. ${ }^{17}$ This cut-off score would also signal the need for further assessment to determine if criteria are met for a depressive disorder. ${ }^{17}$

The Generalised Anxiety Disorder (GAD)-2 scale was used in the study as a brief screening tool for anxiety symptoms. The GAD-2 consists of a two-item Likert scale used to screen for anxiety symptoms over the last two weeks associated with GAD and other common anxiety disorders. ${ }^{18} \mathrm{~A}$ score of three or greater signals that further assessment is required to determine if criteria are met for an anxiety disorder. Previous studies have demonstrated that the GAD-2 questionnaire retains the outstanding psychometric properties of the longer GAD-7 and is an excellent first step screener. ${ }^{19}$ Also, authors have found that the GAD-2 had a sensitivity of $76 \%$ and a specificity of $81 \%$ in their studies. ${ }^{19}$ PHQ-2 and GAD-2 are validated scales with Cronbach's alpha ( 0.83 and 0.81 ) respectively. ${ }^{20}$ In this study, for both $\mathrm{PHQ}-2$ and GAD-2 tools, scores of 0-2 were categorised as 'insignificant depressive or anxiety symptoms' while scores between 3-6 were categorised as 'significant depressive or anxiety symptoms'. Both scales are available in the public domain.

\section{Data Analysis}

Data was analysed using both descriptive and inferential statistics and presented in tables and graphs using Statistical Package for the Social Sciences (SPSS) version 23 (IBM Corp, Armonk, New York, United States). Descriptive statistics were used to analyse the sociodemographic and other characteristics of the participants, tabulated, and reported in frequencies and percentages. Chi-square analyses were performed on categorical data. Binary logistic regression model was used to analyse sociodemographic predictors of depressive and anxiety symptoms which were represented as dichotomous variables reflecting those with 'significant depressive/insignificant depressive symptoms' or those with 'significant anxiety/insignificant anxiety symptoms'. 
RESULTS

\section{Demographics}

There were 485 respondents; 432 (90.8\%) female, 44 $(9.2 \%)$ males. The age range of respondents spanned between 18 and 83 years with the most represented age groups being $31-40$ years (22.2\%) and $41-50$ years (21.9\%). Most persons lived in urban parishes (59.9\%), were affiliated with Christianity (85.4\%), and were single (47.1\%). Table 1 shows the socio-demographic characteristics of participants.

Table 1: Sociodemographic characteristics of participants

\begin{tabular}{|c|c|}
\hline Variables & $\mathrm{n}(\%)$ \\
\hline \multicolumn{2}{|l|}{ Gender } \\
\hline Male & $44(9.2 \%)$ \\
\hline Female & $432(90.8 \%)$ \\
\hline \multicolumn{2}{|l|}{ Age } \\
\hline $18-25$ years & $49(10.5 \%)$ \\
\hline $26-30$ yeas & $72(15.5 \%)$ \\
\hline $31-40$ years & $103(22.2 \%)$ \\
\hline $41-50$ years & $102(21.9 \%)$ \\
\hline $51-60$ years & $96(20.6 \%)$ \\
\hline 60 years and over & $43(9.2 \%)$ \\
\hline \multicolumn{2}{|l|}{ Parish } \\
\hline Urban & $287(59.9 \%)$ \\
\hline Rural & $192(40.1 \%)$ \\
\hline \multicolumn{2}{|l|}{ Religion } \\
\hline None & $51(10.7 \%)$ \\
\hline Christianity & $408(85.4 \%)$ \\
\hline Islam & $2(0.4 \%)$ \\
\hline Rastafarianism & $1(0.2 \%)$ \\
\hline Judaism & $2(0.4 \%)$ \\
\hline Other & $14(2.9 \%)$ \\
\hline \multicolumn{2}{|l|}{ Marital Status } \\
\hline Married & $133(28.5 \%)$ \\
\hline Unmarried & $334(71.5 \%)$ \\
\hline \multicolumn{2}{|l|}{ Employment Status } \\
\hline employed full-time & $212(44.3 \%)$ \\
\hline employed part-time & $40(8.4 \%)$ \\
\hline self-employed & $47(9.8 \%)$ \\
\hline unemployed & $153(31.9 \%)$ \\
\hline retired & $27(5.6 \%)$ \\
\hline \multicolumn{2}{|l|}{ Occupation Category } \\
\hline official/administrator & $72(15.7 \%)$ \\
\hline professional & $149(32.5 \%)$ \\
\hline technician & $7(1.5 \%)$ \\
\hline protective service worker & $10(2.2 \%)$ \\
\hline administrative support worker & $106(23.1)$ \\
\hline skilled artisan/craftsperson & $20(4.4 \%)$ \\
\hline petty trader & $13(2.8 \%)$ \\
\hline unskilled worker & $29(6.3 \%)$ \\
\hline service/maintenance worker & $11(2.4 \%)$ \\
\hline other & $41(9 \%)$ \\
\hline \multicolumn{2}{|l|}{ Education level } \\
\hline Secondary or lower & $90(19.1 \%)$ \\
\hline Vocational & $160(34 \%)$ \\
\hline Undergraduate & $107(22.7 \%)$ \\
\hline Graduate & $114(24.2)$ \\
\hline
\end{tabular}




\section{Changes in Employment Due to COVID-19}

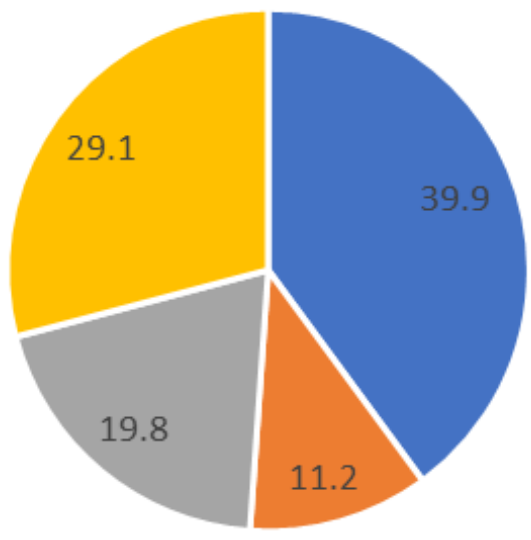

- loss my job a placed on redundancy alary cut get fewer contracts

\section{Knowledge of COVID-19}

Almost all respondents (99.4\%) stated that they had heard of COVID-19. The majority (92.4\%) reported knowing 'a great deal of information' about COVID-19, while others stated that they knew 'some information' (7.2\%) and 'not much information' (0.4\%). A large percentage of respondents reported that COVID-19 is a 'highly infectious disease' (95.5\%), 'primarily passed through droplets from cough or sneeze of an infected person' (97\%) and that 'touching your face increases the chance of COVID-19 virus getting into your body' (96\%).

More than half of the survey respondents (57.2\%) reported that their employment status had changed due to COVID-19. The most significant changes reported by respondents included 'loss of my job' (39.9\%) followed by 'get fewer contracts' (29.1\%).

\section{Depressive and Anxiety Symptoms}

More than half ( $n=255 ; 54.7 \%)$, of respondents reported significant depressive symptoms and almost half of respondents $(n=223 ; 49.2 \%)$ reported significant anxiety symptoms.

Table 2 shows results of chi-square analysis, which revealed significant associations between age, marital status, education level, employment, and changes in employment since COVID-19, types of changes in employment with significant depressive and anxiety symptoms.

The results of binary logistic regression analysis are presented in Table 3. Findings reveal that younger age groups especially those between the ages of 18-25 years were approximately 12 times more likely (odds ratio (OR) $=11.997 ;$; 95\% CI: 3.558-40.463) to have significant depressive symptoms and almost 5 times more likely $(\mathrm{OR}=4.557 ; 95 \% \mathrm{CI}: 01.622-12.803)$ to have significant anxiety symptoms than those 61 years or older. In addition, those with secondary or lower educational and vocational training were more likely to have significant depressive (OR=3.579; 95\% CI: 1.752-7.311 \& OR $=1.970 ; 95 \%$ CI: $1.107-3.508$ respectively) and anxiety symptoms (OR=2.173; 95\% CI: 1.111-4.251 \& $\mathrm{OR}=1.971 ; 95 \% \mathrm{CI}: 1.116-3.484)$ than those who were educated at the postgraduate level.

Those who were employed were less likely to have significant depressive symptoms than those who were unemployed (OR=0.440; 95\% CI: 0.269-0.7217). There were no statistically significant associations found for area of residence or marital status and depressive or anxiety symptoms. 
Table 2. Chi Square analysis of sociodemographic characteristics and significant depressive/anxiety symptoms

\begin{tabular}{|c|c|c|c|c|c|c|}
\hline \multirow[t]{2}{*}{ Variables } & \multicolumn{3}{|c|}{ Depressive Symptoms } & \multicolumn{3}{|c|}{ Anxiety Symptoms } \\
\hline & $\mathrm{n}$ & $\%$ & $x^{2}$ ( $p$ value) & $\mathrm{n}$ & $\%$ & $x^{2}$ ( $p$ value) \\
\hline Age Categories & & & $36.084(<0.01)$ & & & $28.432(<0.01)$ \\
\hline $18-25$ years & 41 & $87.2 \%$ & & 36 & $78.3 \%$ & \\
\hline $26-30$ yeas & 46 & $64.8 \%$ & & 41 & $59.4 \%$ & \\
\hline $31-40$ years & 60 & $59.4 \%$ & & 48 & $49.5 \%$ & \\
\hline $41-50$ years & 47 & $47.5 \%$ & & 46 & $48.4 \%$ & \\
\hline $51-60$ years & 40 & $44.4 \%$ & & 33 & $36.3 \%$ & \\
\hline 61 years and over & 14 & $35.0 \%$ & & 13 & $33.3 \%$ & \\
\hline Area of residence & & & $2.065(>0.05)$ & & & $3.054(>0.05)$ \\
\hline Urban & 14 & $52.1 \%$ & & 12 & $45.8 \%$ & \\
\hline Rural & 10 & $58.9 \%$ & & 98 & $54.1 \%$ & \\
\hline Marital Status & & & $5.163(<0.05)$ & & & $11.068(<0.01)$ \\
\hline Married & 19 & $58.3 \%$ & & 17 & $55.0 \%$ & \\
\hline Unmarried & 59 & $46.5 \%$ & & 48 & $37.5 \%$ & \\
\hline Education level & & & $43.231(<0.01)$ & & & $26.957(<0.01)$ \\
\hline Secondary or lower & 66 & $77.6 \%$ & & 53 & $65.4 \%$ & \\
\hline Vocational & 97 & $62.6 \%$ & & 88 & $58.3 \%$ & \\
\hline Undergraduate & 48 & $45.7 \%$ & & 43 & $42.6 \%$ & \\
\hline Postgraduate & 39 & $34.8 \%$ & & 37 & $33.0 \%$ & \\
\hline Employment status & & & $28.954(<0.01)$ & & & $13.204(<0.01)$ \\
\hline Employed & 13 & $45.0 \%$ & & 12 & $42.9 \%$ & \\
\hline Unemployed & 12 & $70.7 \%$ & & 10 & $60.6 \%$ & \\
\hline Employment status: changed & & & $34.834(<0.01)$ & & & $14.904(<0.01)$ \\
\hline Yes & 17 & $66.3 \%$ & & 14 & $57.0 \%$ & \\
\hline No & 77 & $38.7 \%$ & & 75 & $38.7 \%$ & \\
\hline Type of change to employment & & & $14.150(<0.01)$ & & & $16.908(<0.01)$ \\
\hline Loss of job & 84 & $79.2 \%$ & & 71 & $71.7 \%$ & \\
\hline Placed in redundancy & 19 & $63.3 \%$ & & 13 & $46.4 \%$ & \\
\hline Salary cut & 29 & $58.0 \%$ & & 26 & $51.0 \%$ & \\
\hline Got fewer contracts & 41 & $54.7 \%$ & & 32 & $42.7 \%$ & \\
\hline
\end{tabular}


Table 3. Socio-demographic correlates of depressive and anxiety symptoms

\begin{tabular}{|c|c|c|c|c|c|c|}
\hline \multirow[b]{3}{*}{ Variables } & \multicolumn{3}{|c|}{ Depressive Symptoms } & \multicolumn{3}{|c|}{ Anxiety Symptoms } \\
\hline & \multirow{2}{*}{$\begin{array}{l}\text { Odds } \\
\text { Ratio }\end{array}$} & \multicolumn{2}{|c|}{ 95\% C.I.for EXP(B) } & \multirow{2}{*}{$\begin{array}{l}\text { Odds } \\
\text { Ratio }\end{array}$} & \multicolumn{2}{|c|}{$95 \%$ C.I.for $\operatorname{EXP}(B)$} \\
\hline & & Lower & Upper & & Lower & Upper \\
\hline \multicolumn{7}{|l|}{ Age categories } \\
\hline & $11.997 *$ & 3.558 & 40.463 & $4.557 * *$ & 1.622 & 12.803 \\
\hline \multicolumn{7}{|l|}{$18-25$ years } \\
\hline $26-30$ years & 3.773** & 1.500 & 9.497 & $2.585^{*}$ & 1.058 & 6.322 \\
\hline $31-40$ years & $4.143 * *$ & 1.748 & 9.821 & 2.194 & 0.948 & 5.079 \\
\hline $41-50$ years & 2.062 & 0.866 & 4.913 & 1.916 & 0.822 & 4.466 \\
\hline $51-60$ years & $2.527 *$ & 1.051 & 6.080 & 1.456 & 0.617 & 3.438 \\
\hline Employed/unemployed & $0.440 * *$ & 0.269 & 0.721 & 0.649 & 0.407 & 1.035 \\
\hline \multicolumn{7}{|l|}{ Education level } \\
\hline Secondary or lower & $3.579 * *$ & 1.752 & 7.311 & $2.173^{*}$ & 1.111 & 4.251 \\
\hline Vocational & $1.970 *$ & 1.107 & 3.508 & $1.971 *$ & 1.116 & 3.484 \\
\hline Undergraduate & 1.166 & 0.649 & 2.096 & 1.189 & 0.662 & 2.136 \\
\hline Urban/rural parishes & 1.105 & 0.704 & 1.736 & 0.955 & 0.617 & 1.479 \\
\hline Married/unmarried & 1.044 & 0.653 & 1.669 & 1.431 & 0.904 & 2.267 \\
\hline
\end{tabular}

** Significant at the 0.01 level, *Significant at the 0.01 level

\section{Table 4. Questionnaire Incorporating PHQ-2 and GAD-2 Screeners}

Over the last 2 weeks, how often have you been bothered by the following problems?

\begin{tabular}{|l|l|l|l|l|}
\hline Statements & Not at all & Several days & $\begin{array}{l}\text { More than } \\
\text { half the days }\end{array}$ & $\begin{array}{l}\text { Nearly every } \\
\text { day }\end{array}$ \\
\hline $\begin{array}{l}\text { Little interest or pleasure in doing } \\
\text { things }\end{array}$ & & & & \\
\hline $\begin{array}{l}\text { Feeling down, depressed or } \\
\text { hopeless }\end{array}$ & & & & \\
\hline $\begin{array}{l}\text { Feeling nervous, anxious or on } \\
\text { edge }\end{array}$ & & & & \\
\hline $\begin{array}{l}\text { Not being able to stop or control } \\
\text { worrying }\end{array}$ & & & & \\
\hline
\end{tabular}

\section{DISCUSSION}

The study aimed to assess the effect of COVID-19 on the mental health of Jamaicans in addition to investigating the presence and extent of stigmatising attitudes and behaviours related to COVID-19. This paper speaks specifically to the effect on mental health. We examined the role of a group of select socio-demographic variables (education, age, marital and socio-economic status and rural/ urban location) on depression and anxiety related to coping with COVID-19.

Study participants reported very high levels of knowledge of COVID-19 and its transmission. Previous research has suggested an association between knowledge of COVID 19 and concern about infection of family members and self and may contribute to depressive symptoms. ${ }^{21,22}$ 
Other studies have shown correlations between knowledge and anxiety, fear and psychological distress. ${ }^{23,24}$ However, bivariate and multivariate analysis examining the link between knowledge of COVID-19 and depressive and anxiety symptoms could not be performed due to the high level of awareness of covid-19 (99.4\% of participants). This finding suggests that in our sample, knowledge of COVID-19 was not a likely confounder of the association found between socio-demographic variables and anxiety and depressive symptoms.

The very high levels of knowledge of COVID-19 among study participants also indicates that mass media campaigns geared at educating the public about COVID19 were effective among study participants. However, mass media public education approaches may be inadequate for addressing mental health needs. These approaches can however be adjusted to direct individuals and organizations to sources of help and educate the population on healthy ways to cope with stress related to the epidemic. ${ }^{25}$ In Jamaica, there is a network of Community Mental health services in primary care health centres that can be accessed to provide care. However, mass media education strategies can be augmented with community-based approaches through local level stakeholders such as faith-based organizations and civil society groups including those that serve vulnerable groups like the elderly the physically and mentally challenged within communities. Training and other resources provided to these local agencies can strengthen their capacity to adequately address the needs of those affected by poor mental health

Pandemics are known to pose a threat to the mental health of those at varying levels of risk. ${ }^{26-28}$ Reviews of studies related to COVID- 19 reported a negative impact of the pandemic on the mental health of populations. These studies reported between $16-18 \%$ prevalence of symptoms of anxiety and depression. ${ }^{3,25}$ One of the largest reported effects on mental health related to COVID-19 is from the United States where $45 \%$ of adults reported anxiety and stress. ${ }^{29}$ Similar to findings of Choi et al which revealed that anxiety is frequently comorbid with depression, more than half of the respondents in our study reported depressive symptoms and almost a half also reported symptoms of anxiety. ${ }^{30}$

The predictive factors for depressive symptoms also apply to symptoms of anxiety as reported by Ahmed et al in their study in China. ${ }^{31}$ Our study established that younger age, lower educational status and unemployment were associated with both depressive and anxiety symptoms. Early evidence from other sources indicate that women, younger age and persons with poor sleep quality are at higher risk for poor mental health outcomes. ${ }^{32-34}$ Respondents in our study were predominantly female $(90.8 \%)$, however, sleep quality before COVID-19 was not explored. In contrast to studies by Gao et al and Lei et al, this study showed that marital status was not associated with depressive and anxiety symptoms. ${ }^{35,36}$ The reason for our finding is unclear but might be related to the social organization of the domestic unit in the Jamaican society where the extended family system ostensibly cushions the effects of being single, divorced or widowed. ${ }^{37}$ Another area of contrast with previously published studies was the association between urban living and anxiety and depression symptoms. ${ }^{31,33,34}$ There was no association between rural-urban dwelling and these specific mental health effects of COVID-19 in this study.

Adverse changes in employment status were singularly the most significant impact of the COVID-19 epidemic in the tourism-dependent region of the Caribbean, including Jamaica. The International Labour Organization reported a loss of over 34 million jobs in Latin America and the Caribbean at the end of the third quarter of $2020 .{ }^{38}$ Loss of income, job and /or business was the most significant effect reported in our study as the majority of the sample had been affected in this way. This negative change in employment status was significantly associated with both depressive and anxiety symptoms. Unemployment is listed among significant risk factors for developing symptoms of mental disorders especially depressive symptoms. $35,36,39,40$

There is an inherent responsibility of public health agencies to address the adverse mental health effects of national epidemics like COVID-19. Public health actions, such as social distancing, though necessary to reduce spread of the disease, can make people feel isolated and lonely and can increase stress and anxiety. Our study corroborates the literature from other parts of the world showing that anxiety and depression related to the novel nature of the COVID 19 pandemic and uncertainty about what could happen can be overwhelming and cause strong emotions. Public education must therefore at the minimum create an awareness of the possible mental 
health effects of COVID-19 and the measures put in place to address transmission. The symptoms of anxiety, stress and depression are not always well recognised. Families including parents, care- givers and health- care providers should be able to recognise the symptoms and be guided to initiate suitable responses including seeking care and referral.

The findings of this study indicate that those who became unemployed or experienced significantly reduced income were more likely to experience depression and anxiety. In the initial four months of the epidemic in Jamaica the government offered tangible support through monetary grants, food and sanitization packages and enhanced access to medication to the most affected particularly in quarantined communities. These practical measures provide hope and a sense of support but may not be sustainable in a developing country such as Jamaica.

A coordinated approach that is evidence based should be implemented at the national level by the Ministry of Health and its stakeholders. Studies such as ours provide evidence for building an appropriate and adequate response.

\section{Strengths and limitations}

This study has some strengths. First, it used a pre-tested questionnaire (with components from well-known mental health screening tools) to carry out a nation-wide survey to meet the urgent need of assessing the perceptions of the general public on aspects of the novel coronavirus COVID19. The use of a rapid online survey allowed for this research to be conducted in accordance to public health measures during the current pandemic. Second, a multivariate analysis was conducted using logistic regression to assess for independent factors associated with depressive and anxiety symptoms. Third, it is one of the first studies to systematically evaluate the influence of COVID-19 on mental health in Jamaica, and in the Caribbean region.

However, this study is not without limitations. A concern is the over-representation of females in the study as $90 \%$ of the participants were female. This study was conducted between August and September 2020. The rapidly changing context of the pandemic may also affect the generalizability of our findings.

There are also limitations associated with the use of online survey, as with all methods. This study might not have captured certain populations that did not have Internet access to respond to the questionnaires. Similarly, the sample may disproportionately include individuals who, by reason of demographic or social and economic factors have and maintain social media accounts. This may lead to selection bias. ${ }^{16}$ Furthermore, the self-report aspect of the questionnaire without having a researcher on hand to answer any questions does pose its own challenges. This, however, was mitigated in this study through the prior testing of the questionnaire for ease of comprehension and completion, as has previously been practised by other researchers. ${ }^{16}$ Additionally, the use of brief screening tools to assess for depression and anxiety symptoms were limited to a two week recall history and not specific to the onset of the pandemic. Hence, other factors could contribute to these symptoms such as overall stressor of experiencing a pandemic, among others. ${ }^{41}$ This would require additional history beyond the scope of this study. Lastly, being a cross sectional study, it was not possible to establish causality between explanatory and outcome variables; nevertheless, our findings may contribute to the understanding of the mental health effects on the population during a COVID-19 outbreak.

\section{CONCLUSION}

COVID-19 pandemic has posed a multi-faceted challenge in the world, including the small island of Jamaica. Findings from this study highlight the need for government and nongovernmental agencies to develop targeted mental health initiatives for those found to be most at risk of exhibiting depressive and anxiety-related symptoms. Those most at risk were found to be young adults, the under- or unemployed and those with lower levels of education.

\section{RECOMMENDATIONS}

COVID 19 and its effects seem to be associated to poor mental health in Jamaica. Addressing the mental health impact of COVID-19 in the country therefore needs to be prioritized. Programmes and services should be developed to address the effects of the pandemic on the mental health of the population. Both mental health and psychosocial support need to be integrated into the pandemic response. Coping strategies should be promoted through mass media and other communication strategies used by the health services. Given the diversity among those most-at-risk, interventions should be tailored to fit 
the uniqueness of the situations surrounding those most vulnerable. Training of facility and community-based health workers needs to be coordinated, while guidelines for mental health support during outbreaks need to be made available and disseminated to all providing services.

Ethical Approval Statement: Ethical Approval for the study was granted through the Ministry of Health and Wellness Research Advisory Panel on Ethics and MedicoLegal Affairs Committee as well as from the University of the West Indies Faculty of Medical Sciences Ethical Research Committee.

Conflict of Interest Statement: The authors have no competing interests to disclose.

Informed Consent Statement: Not Applicable Funding Statement: No funding was provided for this project.

\section{Author Contributions: Patrice Whitehorne-Smith} contributed to the conceptualisation of study design, drafting of the research protocol, development of survey instrument, data analysis for paper, writing of the abstract and methodology, critical review of the manuscript and approval of the manuscript for submission. Gabrielle Mitchell contributed to the conceptualisation of the study design, preparation of the documents for submission for ethical review, the drafting of the introduction, the formatting of the document for submission to this journal, and approval of the manuscript for submission. Althea Bailey contributed to the design of the study and writing of the paper and approval of the manuscript for submission. Chinwendu Agu contributed to the conceptualisation of project and general methodology, review of the manuscript and approval of the manuscript for submission. Kayan Campbell Williams contributed to the editing and revision of the manuscript and approval of the manuscript for submission. Daniel Oshi contributed to the conceptualisation and design of the study, drafting of the research protocol, study implementation, and critical revision of the manuscript for important intellectual content, and approval of the manuscript for submission. Joy Harrison contributed to the formation of the paper, the critical review of the manuscript and approval of the manuscript for submission. Wendel Abel contributed to the conceptualisation and design of the study and approval of the manuscript for submission.

\section{REFERENCES}

1. World Health Organisation (WHOa). (2020). Coronavirus (COVID-19). 2020. Retrieved from https:// covid19.who.int/

2. World Health Organization. (2020) 2019-nCoV outbreak is an emergency of international concern. 2020. http:// www.euro.who.int/en/health-topics/emergencies/ pages/news/news/2020/01/2019-ncov-outbreak-is-anemergency-of-international-concern (access Feb 16, 2020)

3. Rajkumar RP. COVID-19 and mental health: A review of the existing literature. Asian Journal of Psychiatry 2020 Aug;52:102066. doi: 10.1016/j.ajp.2020.102066. Epub 2020 Apr 10. PMID: 32302935; PMCID: PMC7151415.

4. Verma S, Mishra A. Depression, anxiety, and stress and socio-demographic correlates among general Indian public during COVID-19. International Journal of Social Psychiatry 2020 Dec;66(8):756-762. doi: 10.1177/0020764020934508. Epub 2020 Jun 20. PMID: 32567466.

5. Alrubaiee GG, Al-Qalah TAH \& Al-Aawar MSA. Knowledge, attitudes, anxiety, and preventive behaviours towards COVID-19 among health care providers in Yemen: an online cross-sectional survey. BioMed Central Public Health 2020; 20, 1541. https:// doi.org/10.1186/s12889-020-09644-y

6. Des Jarlais DC, Galea S, Tracy M, Tross S, \& Vlahov, D. Stigmatization of newly emerging infectious diseases: AIDS and SARS. American Journal of Public Health 2006; 96(3), 561-567. https://doi.org/10.2105/ AJPH.2004.054742

7. Smith, R.A., Hughes, D. Infectious Disease Stigmas: Maladaptive in Modern Society. Communication Studies 2014; 65(2): 132-138. doi:10.1080/10510974.2013.851096

8. Brooks SK, Webster RK, Smith LE, Woodland L, Wessely S, Greenberg N, Rubin GJ. The psychological impact of quarantine and how to reduce it: rapid review of the evidence. The Lancet 2020;Mar 14;395 (10227):912-920. doi: 10.1016/S0140-6736(20)304608. Epub 2020 Feb 26.

9. Hawryluck L, Gold WL, Robinson S, Pogorski S, Galea S, \& Styra R. SARS Control and Psychological Effects of Quarantine, Toronto, Canada. Emerging Infectious Diseases 2004; 10(7), 1206-1212. doi: 10.3201/ eid1007.030703 
10. Lee S, Chan LY, Chau AM, Kwok KP \& Kleinman A. The experience of SARS-related stigma at Amoy Gardens. Social Science \& Medicine 2005; 61(9), 2038-2046. doi: 10.1016/j.socscimed.2005.04.010

11. Jeong H, Yim HW, Song Y-J, Ki M, Min J-A, Cho J, \& Chae $\mathrm{J}-\mathrm{H}$. Mental health status of people isolated due to Middle East Respiratory Syndrome. Epidemiology and Health 2016; 38. doi: 10.4178/epih.e2016048

12. Johal, SS. Psychosocial impacts of quarantine during disease outbreaks and interventions that may help to relieve strain. The New Zealand Medical Journal 2009;122(1296):47-52.

13. Centers for Disease Control and Prevention (CDC). Coronavirus Disease 2020. 2020. Retrieved April 23, 2020, from https://www.cdc.gov/coronavirus/2019ncov/cases-updates/summar.html

14. Gong W, Taighoon Shah M, Firdous S, Jarrett BA, Moulton LH, Moss WJ, et al. Comparison of three rapid household survey sampling methods for vaccination coverage assessment in a peri-urban setting in Pakistan. International Journal of Epidemiology 2019. April 1;48(2):583-95. doi: 10.1093/ije/dyy263

15. Geldsetzer P. Use of Rapid Online Surveys to Assess People's Perceptions During Infectious Disease Outbreaks: A Cross-sectional Survey on COVID-19. Journal of Medical Internet Research 2020; 22(4), e18790. https://doi.org/10.2196/18790

16. Boni, RBD. Web surveys in the time of COVID-19. Cadernos de Saúde Pública 2020; 36(7), e00155820. Epub July 03,2020. https://doi.org/10.1590/0102$311 \times 00155820$

17. Kroenke K, Spitzer RL, Williams JB. The Patient Health Questionnaire-2: Validity of a Two-Item Depression Screener. Medical Care 2003;41:1284-92.

18. Kroenke K, Spitzer RL, Williams JB, Monahan PO, Löwe B. Anxiety disorders in primary care: prevalence, impairment, comorbidity, and detection. Annals of Internal Medicine 2007; 146:317-25.

19. Plummer F., Manea L., Trepel D., McMillan D. Screening for anxiety disorders with the GAD-7 and GAD-2: a systematic review and diagnostic metaanalysis. Gen Hosp Psychiatry. 2016; 39:24-31. doi:10.1016/j.genhosppsych.2015.11.005.

20. Staples LG., Dear BF., Gandy M., Fogliati V., Fogliati R., Karin E., Olav Nielssen N., Titov N. Psychometric properties and clinical utility of brief measures of depression, anxiety, and general distress: The PHQ-2,
GAD-2, and K-6. Gen Hosp Psychiatry. 2019;56:13-18. doi: 10.1016/j.genhosppsych.2018.11.003

21. Roy D, Tripathy S, Kar SK, Sharma N, Verma SK, Kaushal V. Study of knowledge, attitude, anxiety \& perceived mental healthcare need in Indian population during COVID-19 pandemic. Asian J Psychiatr. 2020 Jun;51:102083. doi: 10.1016/j.ajp.2020.102083. Epub 2020 Apr 8. PMID: 32283510; PMCID: PMC7139237

22. Zhao B, Kong F, Aung MN, Yuasa M, Nam EW. Novel Coronavirus (COVID-19) Knowledge, Precaution Practice, and Associated Depression Symptoms among University Students in Korea, China, and Japan. Int J Environ Res Public Health. 2020 Sep 13;17(18):6671. doi: 10.3390/ijerph17186671. PMID: 32933212; PMCID: PMC7558700.

23. Saravanan C, Mahmoud I, Elshami W, Taha MH. Knowledge, Anxiety, Fear, and Psychological Distress About COVID-19 Among University Students in the United Arab Emirates. Front Psychiatry. 2020 Oct 22;11:582189. doi: 10.3389/fpsyt.2020.582189. PMID: 33192728; PMCID: PMC7642490.

24. Maarefvand M, Hosseinzadeh S, Farmani O, Safarabadi Farahani A, Khubchandani J. Coronavirus outbreak and stress in Iranians. Int J Environ Res Public Health. (2020) 17:4441. doi: 10.3390/ijerph17144915

25. Vindegaard N, Benros ME. COVID-19 pandemic and mental health consequences: systematic review of the current evidence. Brain, Behavior, and Immunity 2020; 89:531-542. doi: 10.1016/j.bbi.2020.05.048.

26. Mak IW, Chu CM, Pan PC, Yiu MG, Chan VL. Long-term psychiatric morbidities among SARS survivors. General Hospital Psychiatry 2009; Jul-Aug;31(4):318-26.

27. Mak IW, Chu CM, Pan PC, Yiu MG, Ho SC, Chan VL. Risk factors for chronic post-traumatic stress disorder (PTSD) in SARS survivors. General Hospital Psychiatry 2010 Nov-Dec;32(6):590-8.

28. Lung FW, Lu YC, Chang YY, Shu BC. others. Mental symptoms in different health professionals during the SARS attack: a follow-up study. Psychiatry Quarterly 2009; Jun;80(2):107-16.

29. Panchal N, Kamal R, Orgera K, Cox C, Garfield R, Hamel L, Muñana $C$, and Chidambaram $P$. The Implications of COVID-19 for Mental Health and Substance Use. Available from:https://www.kff.org/ coronavirus-covid-19/issue-brief/the-implications-ofcovid-19-for-mental-health-and-substance-use/.

30. Choi K.W., Kim Y., Jeon H.J. Comorbid Anxiety and 
Depression: clinical and Conceptual Consideration and Transdiagnostic Treatment. Advances in Experimental Medicine and Biology 2020;1191:219-235. doi: 10.1007/978-981-32-9705-0_14

31. Ahmed M.Z., Ahmed O., Zhou A., Sang H., Liu S., Ahmad A. Epidemic of COVID-19 in China and associated psychological problems. Asian Journal of Psychiatry 2020;51

32. Liu N, Zhang F, Wei C, Jia Y, Shang Z, Sun L, et al. Prevalence and predictors of PTSS during COVID-19 outbreak in China hardest-hit areas: gender differences matter. Psychiatry Research 2020 May;287:112921.

33. Wang C, Pan R, Wan X, Tan Y, Xu L, Ho CS, et al. Immediate psychological responses and associated factors during the initial stage of the 2019 coronavirus disease (COVID-19) epidemic among the general population in China. International Journal of Environmental Research and Public Health 2020; Mar;17(5):1729.

34. Huang Y, Zhao N. Mental health burden for the public affected by the COVID-19 outbreak in China: who will be the high-risk group? Psychology, Health \& Medicine 2020; 23-34. doi: 10.1080/13548506.2020.1754438.

35. Gao J., Zheng P., Jia Y., Chen H., Mao Y., Chen S., Wang Y., Fu H., Dai J. Mental health problems and social media exposure during COVID-19 outbreak. PLOS ONE. 2020; 15(4) doi: 10.1371/journal.pone.0231924.

36. Lei L., Huang X., Zhang S., Yang J., Yang L., Xu M. Comparison of prevalence and associated factors of anxiety and depression among people affected by versus people unaffected by quarantine during the covid-19 epidemic in southwestern China. Medical Science Monitor 2020; 26 doi: 10.12659/MSM.924609

37. Forsythe-Brown I, Taylor RJ, Chatters LM, Govia IO, Matusko N, Jackson JS. Kinship Support in Jamaican Families in the USA and Jamaica. J Afr Am Stud (New Brunsw). 2017;21(2):187-202. doi:10.1007/s12111017-9355-7

38. ILO Labour Overview 2020 https://www.ilo.org/ caribbean/newsroom/WCMS_735506/lang--en/ index.htm

39. Mazza C., Ricci E., Biondi S., Colasanti M., Ferracuti S., Napoli C., Roma P. A nationwide survey of psychological distress among Italian people during the COVID-19 pandemic: immediate psychological responses and associated factors. International Journal of Environmental Research and Public Health
2020;17:3165. doi: 10.3390/ijerph17093165.

40. Olagoke A.A., Olagoke O.O., Hughes A.M. Exposure to coronavirus news on mainstream media: the role of risk perceptions and depression. British Journal of Health Psychology 2020; 24(4): 865-874. doi: 10.1111/bjhp.12427.

41. Khademian, F., Delavari, S., Koohjani, Z. et al. An investigation of depression, anxiety, and stress and its relating factors during COVID-19 pandemic in Iran. BMC Public Health 21, 275 (2021). https:// doi.org/10.1186/s12889-021-10329-3 